\title{
The Effect of Image-Schema-Based Instruction on Learning/ Acquiring Polysemous Prepositions
}

\begin{abstract}
:
Polysemous prepositions represent a real challenge for students and teachers alike. The many meanings of these words have always been pedagogically treated in a piecemeal fashion and as largely arbitrary. This makes their learning more complicated because learners keep on experiencing difficulty with their semantics. However, the use of a new way to teach polysemous prepositions such as applying image-schemas seems to be very promising. This paper aims at presenting the characteristics of the semantics of polysemous prepositions and reports on an experimental study which examines the efficacy of image-schema-based instruction on learning the semantics of the English prepositions above, across, in, on, out, over and through. It also investigates the students' attitudes towards the usefulness of this form of instruction. Eighty students studying English as a foreign language at the University des Fréres Mentouri, Constantine were chosen randomly. They were divided into a Control Group and a Treatment Group. Comparisons of pretest and post-test results show that the group who received instruction based on image-schemas experienced a dramatic change in their understanding of the semantics of the target prepositions. On the basis of the results of the students' questionnaire and experiment, it can be deduced that image-schema-based instruction plays an important role in improving the learning of polysemous prepositions, and it can serve as a vital tool in teaching them.
\end{abstract}

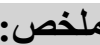

تمثل حروف الجر متعددة المعاني تحد حقيقي للطلبة و الأساتذة على حد سو اء. هذه المعاني

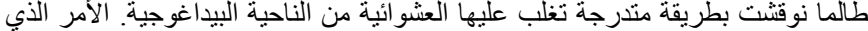

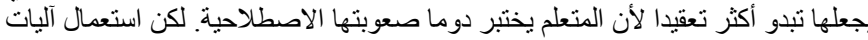

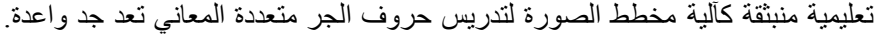

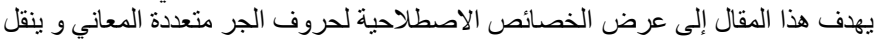

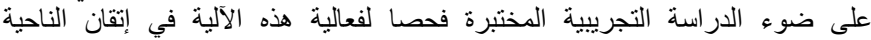

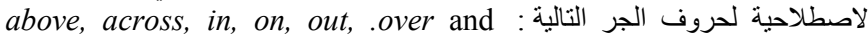
through

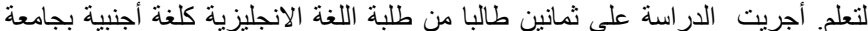

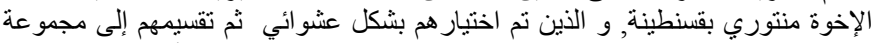

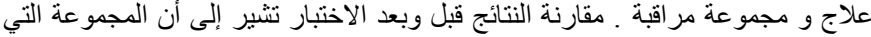

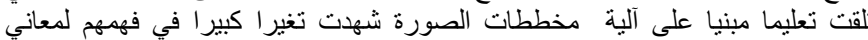

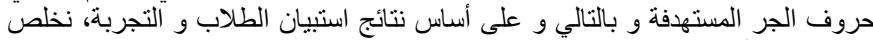

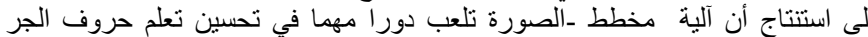
متعددة المعاني ، و أنها يمكن أن تكون بمثابة أداة حيوية في تعليمهر.

\section{Hasna Lamis BOUCHENEK}

Faculty of Letters and Languages

Department of Foreign Languages

University of Mentouri

Constantine

\section{Introduction :}

When learning English, building up a comprehensive understanding of how to use prepositions properly is one of the most difficult feats learners of English accomplish. On first inspection, prepositions are characterized by a high degree of polysemy. The same preposition can be used in many contexts, each of which conveys a different meaning. It is a colossal task for students to realize the potential reason behind this polysemantic nature. 
In terms of instruction, teachers cannot define the meanings without using other ones in the explanation. The latter turns out often to be vague and confusing since prepositions are not perfectly synonymous. Furthermore, traditional accounts have always treated their meanings as unsystematic. They have provided little aid to learners because they just consolidate rote memorization of them. Consequently, students are left frustrated about getting a fragmented picture of the nuances between these words, with an apprehension that polysemous prepositions constitute a semantic labyrinth which is better not to be given a great attention. Lam (2009) found out that using correctly the spatial language is among the last aspects learned, and even learners with an advanced level are not able to reach a native speaker-like use (cited in Tyler, Mueller \& Ho, and 2010a).

In the light of these problems, the current issue to be considered here is how to improve the learning of polysemous prepositions and raise the students' awareness of the different meanings so that they can use them correctly. One way is to adopt the theory of image-schema. It offers an alternative perspective, suggesting that the meanings of polysemous prepositions are image-schematic in nature and systematically motivated. For the purpose of this paper, our study sheds light on the prepositions above, across, in, on, out, over and through. It aims at testing the effectiveness of using image-schemas in their learning and teaching. It discusses their semantic differences together with providing a theoretical overview of the notion of image-schema with that of polysemy. Finally, the study ends up with presenting the students' views towards applying image-schemas in the learning and teaching of polysemous prepositions.

\section{The Notion of Polysemy in Linguistics}

Polysemy has always been considered an issue in linguistic research. However, its new conception in Cognitive Linguistics has helped to have a clearer understanding of its ubiquity in languages.

\subsection{What is Polysemy}

Polysemy is widely used to refer to the phenomenon of words that have more than one meaning. It was popularized and introduced into general linguistics by the French semanticist Michal Bréal in 1887 (Nerlich, 2003). Even though the term polysemy is commonly used to refer to the plurality of meaning, it is worth to emphasize that words carrying more than one meaning are not particularly polysemous. The conception of polysemy is not yet a clearcut one because it overlaps with homonymy, which is described as an instance of meaning variation too. Because of this fact in semantic theory, several attempts have been made to differentiate between them. While polysemy involves one form with a wide range of meanings, homonymy represents a relation that connects between two separate lexemes. Homonymy refers to words which are spelled and sound exactly the same, but their meanings are different (Murphy, 2010). For example, the noun 'ring' which means 'circular 
band' and the verb 'ring' which means 'to make a bell sound' are two unconnected words with distinct senses $(1)$ They coincidentally share the same spelling and pronunciation (Denning, Kessler \& Leben, 2007, p. 137). The distinction between homonymy and polysemy is not all the time definite as it may seem. Lipka (2002) asserts that both of them are not absolute opposites, but they must be regarded as "two end-points of a scale with a continuum in between" (p. 157). The reason for this is that these two phenomena continue to overlap with each other in some cases where they appear to be almost the same. Hence, instead of a dichotomy between the two, we can say that there is a graded continuum of meaning going from homonymy at one end to polysemy at the other end.

The traditional conception of polysemy has remarkably been changed with the arrival of Cognitive Linguistics. Within Cognitive Linguistics, the main characteristic of a word to be polysemous is not only the plurality of its meanings, but the fact that these meanings are naturally, systematically and not arbitrarily connected (Saeed, 2009). A word is polysemous if it has a basic meaning which is termed the core or the primary meaning, and the latter can serve as the base for the other secondary or figurative senses to extend systematically and naturally (McGregor, 2009). For instance, the verb 'to feed' in 'to give food to someone/ something or 'to eat food' has a literal usage versus 'to feed your imagination' and 'to feed lines to an actor' are figurative usages (Knowles \& Moon, 2006, p. 16). The reason for this extension can be explained by the fact that people find it easier to use the same words and expand their meanings instead of creating new ones (Murphy, 2002). The emergence of new meanings in an individual word safeguards the language system. That is, without this semantic extension, the vocabulary would increase infinitely; we would need a bulk of unique words to express our ideas in order to refer to the unlimited things in the world. It is no wonder then that it was thought of polysemy as a 'healthy' characteristic of languages (Ricoeur, 1977).

\subsection{Types of Polysemy}

Metaphor and Metonymy are two ways of construing new meanings from old ones to generate polysemy. They were traditionally studied as literary devices. Nevertheless, since the emergence of Cognitive Linguistics, they have started to be regarded as central features of human thought and language.

Metaphors are developed by people because there is no direct way of understanding certain abstract concepts of human knowledge. They are used to comprehend complex (or abstract) concepts such as emotions by connecting them to better-known, easier to understand concepts (Radden \& Dirven, 2007). That is, the properties of the primary sense of a word are transferred to an abstract concept because they may share some abstract similarities. As an example, consider the word "brain." In addition to its basic sense, it is used for electronic devices, as in, "the microprocessor is the brain of a computer." This 
secondary sense is metaphorically motivated. In English, the domain of electronics (the complex concept) is understood in terms of human beings (the concrete concept). The way a microprocessor functions in the computer (i.e. it handles all data that goes through the computer) is conceptualized in terms of the way the brain functions in human beings (Radden \& Dirven, 2007, p. 1216).

Metonymy is another important way people use to convey information to each other. It refers to linguistic expressions where a word is substituted by another one which is tightly connected to it (Radden \& Kôvecses, 1999). When producing metonymical linguistic expressions, people are likely to pick out a particular element of something to represent the thing as a whole concept. They use it as "a point of access" to the entire concept. For instance, In English, one of the secondary senses of the word "crown" is developed by means of metonymy. The crown is a part of a monarch's attire. It is an object made of gold and precious stones worn by the king or the queen. The crown is also the symbol of its royal wearer and, more abstractly, of the monarchy. It is the distinguishing feature we never miss out. The shift in meaning occurs by taking the easily perceived aspect, the crown, as a reference point to provide a mental access to another conceptual entity (the monarch). Accordingly, speakers of English added a new meaning to the word "crown" by using a well understood part ( the crown) to stand for a whole (the monarch, or the monarchy ) which can be found in sentences like, "the crown never rejects a bill approved by Parliament” (Radden \& Dirven, 2007, p. 14).

\section{Image-schema and Image-Schema -Based Instruction}

An image-schema is a key concept of Cognitive Semantics which helps us understand the meanings of a given word in a more meaningful way.

\subsection{Image-schema}

The theory of image-schema was first articulated by Mark Johnson in 1987. It was originated in philosophy, but it has been developed in Cognitive Semantics which is a branch of Cognitive Linguistics. Cognitive semantics holds that meanings are in the head, and they are likened to concepts in people's mind (Evans, 2007). Researchers like (Johnson, 1987; Cienki, 1998) assert that concepts are not structured in our minds in the form of semantic features or represented in a way that resembles words (as cited in Evans \& Tyler, 2005). Conceptual representations are in the form of what termed by Mark Johnson (1987) image-schemas. Therefore, image-schemas are relatively abstract conceptual representations that are formed directly from using our bodies to interact with and observe the world around us (Evans \&Green, 2006). 
They represent (or summarize) information about the spatial relationships between objects and the physical movement in the world (Mandler \& Pagán Cánovas, 2014). Empirical support for these views come from experimental research by Gibbs and Colton in 1995 in psycholinguistics, cognitive psychology and development psychology (as cited in Croft\& Cruse, 2004).

Image-schemas are not images. Evans \& Green (2006) argue that images are fundamentally different from image-schemas because they contain many details concerning their own shapes and colours. Mental images are the consequence of a conscious cognitive process which requires recalling visual memory. We can close our eyes, imagine the face of a any person, but we cannot bring into awareness an image-schema. "Image-schemas are buried 'deeper' within the cognitive system [...] and as such are not available to conscious introspection" (Evans \& Green, 2006, p.186). They are more abstract, general and schematic than ordinary images. In another sense of that term, image-schemas are schematic versions of images (Croft \& Cruse, 2004).

To get the idea of image-schemas, cognitive linguists illuminate their description with diagrams. Evan and Green (2006) point out that the benefit of diagrams is to represent concepts without relying on language so that linguistic meaning is shown in an economical and memorable way. Gärdenfors (2007) goes on to say, the schematic diagrams are not meant to liken a picture of how the world looks like or to resemble a mental picture, instead they are solely simple visual aids (schemas) that show the main constituents of every imageschema. In fact, many semantic analyses have made use of image-schemas as a tool to describe most notably the meanings of prepositions, modal verbs and verbs. Some of the studies mentioned by Soares da Silva (2003) include the study of over by Brugman (1981), Lakoff (1987) and Dewell (1994), the analysis of take by Norvig and Lakoff (1987), the study of stand by Gibbs (1995).

\subsection{Image-schema-Based Instruction}

By definition, image-schema-based instruction is "a form of vocabulary instruction in which the process of learning a word is mediated by the use of image-schema" (Morimoto \& Loewen, 2007, p. 351). When applying imageschema-based instruction, the teacher does not teach the many meanings of a word exhaustively, but rather it aims at giving "learners with a basis on which they can effectively process the various meanings in subsequent input" (Morimoto \& Loewen, 2007, p. 351). Researchers (e.g. Ruhl, 1989; Tyler and Evans, 2004) claim that if learners become more conscious of the underlying core meaning of a given polysemous word, this can serve as a basis for comprehending figurative usages (cited in Morimoto \& Loewen, 2007). Csábi (2004) states that learners who are made aware of how the cognitive mechanisms (metaphors and metonymies) make up the meanings of polysemous words will learn and use them easily than those who are not taught 
this fact. In effect, this can increase learners' ability to grasp, internalize as well as transmit what is learned, allowing them to use the language appropriately. In brief, image-schema-based instruction involves going beyond the surface meaning of words.

\section{Polysemous Prepositions}

A preposition with several meanings has a central sense which involves two elements, called trajector and landmark, on the basis of which, we can account for the relationship between the senses.

\subsection{Trajector and Landmark}

Every English preposition primarily expresses a spatial relation to show the position or the motion of one entity, called the figure, with respect to another, the ground, which acts as a reference point entity. In this paper, Langacker's terms will be adopted (1987), namely, trajector and landmark. We will refer to the figure entity as the 'trajector' (TR) and the ground entity as the 'landmark' (LM). Typically, the TR is the most prominent entity in the spatial scene profiled by the preposition. It is smaller, mobile and geometrically simpler, while the LM is larger, more complex and more stationary (Taylor, 1993; Croft\& Cruse, 2004; Brenda, 2014). Given the sentence, 'the book is on the desk,' 'the book' describes the TR, 'the box' the LM. The preposition 'on' joins them through designating the location of 'the book' in relation to 'the table'.

\section{2 The Semantics of above, across, in, on, out, over and through}

In this section, we present a general analysis of the prepositions above, across, in, on, out, over and through in order to give the reader an idea about the theoretical foundations upon which we used in the instruction employed in the study. The reason behind choosing these prepositions lies in the fact that their semantics are difficult to characterize. Space limitation will not allow us to discuss all the extended meanings in full detail. We, therefore, include here a brief summary of the main senses.

\section{- Above}

In its spatial primary sense, above expresses a motionless state where a TR is higher than a LM. The most representative central image-schema of above can look as follows:

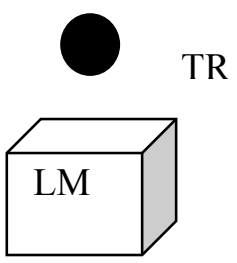


Figure 01: The Central Image-Schema of above

Figure 1 shows the graphic representation of above, as used in the sentence, 'it is enjoyable to see the blue sky and the clouds above us in daytime'. As the figure shows, the TR (the circle) and the LM (the cube) are not in contact. It entails that the relation profiled by above suggests an absolute separation between the TR and the LM (Lindstromberg, 2010).

In another usage, above denotes a dynamic state where it retains the meaning that the TR is higher than the LM, however, in this case, it refers to the endpoint of a path (Lindstromberg, 2010). Figure 2 depicts this sense:

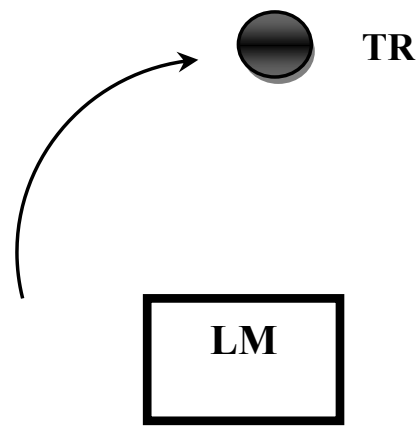

Figure 02: Image-Schema of above When Expressing Motion (adapted from

\section{Lindstromberg, 2010, p. 111)}

In this figure, the arrow reflects the movement and orientation of the TR to a point that is higher than and not in contact with the LM, like it is used in, 'let's hang a picture above the sofa'. The notion of separation expressed by above is extended to refer to non-spatial senses. Metaphorically, above is used to mean that a given TR is detached, has no access and effect on the LM, as in, 'the actions of public officials must be above suspicion (has no contact with dishonest practices)' (Lindstromberg, 2010, p. 117). 
- On

Unlike above, on denotes support and contact. The LM supports the TR so that it does not fall (Lindstromberg, 2010). Its different spatial senses are represented in figure 3 :

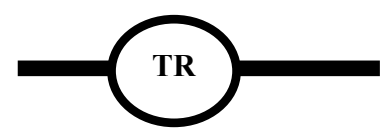

(a)

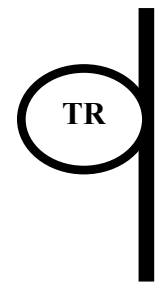

(b)

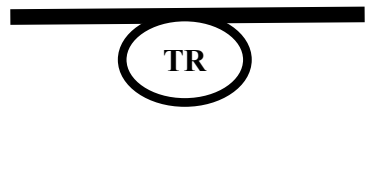

(c)

Figure 03: The Spatial Senses of on (Adapted from Lindstromberg, 2010, p. 51)

The (a) image-schema could serve as the basic schema of on. It could refer to the use of on in a context like, 'the laptop is on the desk.' In the first schema, the circle represents the laptop. The latter is supported and touches the upper

surface of the desk which is represented by the line. The schemas (b) and (c) show that on is employed when the physical arrangement in the central sense is rotated. The (b) schema applies to a context like, '[the] picture [is] on the wall,' in which case the picture is supported and in contact with the wall (Coventry \& Garrod, 2004, p. 53). The (c) schema would be needed for 'the bug is on the ceiling', and 'the chewing gum is on the bottom of the table' (Lindstromberg, 2010, p. 52).

The relationship conveyed by on is metaphorically extended to abstract domains. On is used to talk about TRs like unwelcome events and states as if they were burdens. Lindstromberg (2010) claims that if the TR supports the LM, then the TR is considered as a burden from the perspective of the LM. "[The events and states] are likened to physical burdens borne by the LM. From one's own point of view, an unwelcome [TR] is 'on' oneself, for example, "shame on you" (p. 61).

\section{- Across}

The spatial meaning of across refers to paths. It expresses the movement of a TR from one side of a LM to the other; the side directly opposite (Yates, 1999; Lindstromberg, 2010). This meaning is shown in figure 4: 


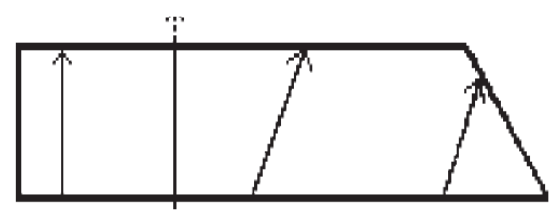

Figure 04: Diagrammatic Representation of across (adapted from

Lindstromberg, 2010, p. 123)

LM

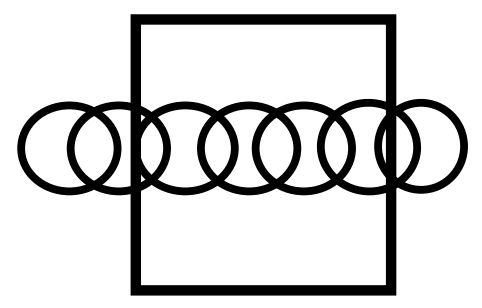

TR

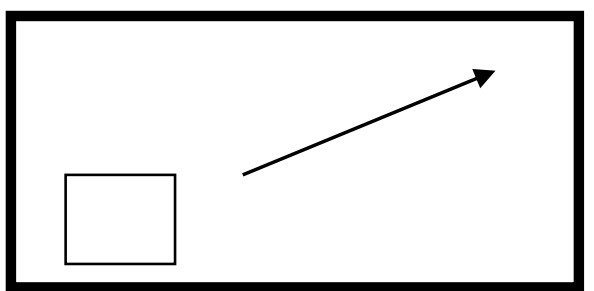

In this figure, the arrows depict the movement and the direction of the TR. Typical examples of this meaning include, 'they walked across the desert' and 'people are moving across the street'. Metaphorically, across is not employed as much as the above discussed prepositions, but it is commonly used with verbs. Again, due to space limitation, only the verb come across will be discussed. Come across in the sentence, 'I came across a question in a forum that triggered my interest,' means 'to encounter it by chance'. Lindstromberg (2010) proclaims that when we move from one side to the other side of a route, we encounter someone else coming from one side or another. Experiencing such meeting may have led to the original image behind come across.

\section{- Over}

The preposition over has three spatial senses which are termed the aboveacross sense, the above-sense and the covering sense (Lakoff, 1987; cited in Riemer, 2010, p. 244- 255). These senses are shown respectively in the following image-schemas: 


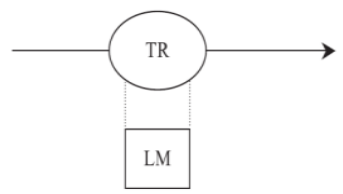

The above-across sense

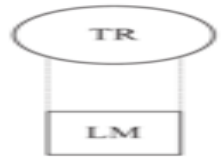

The above sense

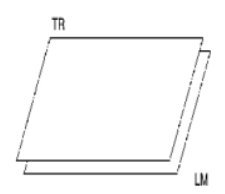

The covering sense

\section{Figure 05: The Spatial Senses of Over}

In the case of the above-across sense, the TR (the circle) moves along a path represented by an arrow. The TR is above and has no contact with the LM. The TR moves across the boundaries of the LM which are depicted by the dotted lines. The first schema, which is the most central one, can be expressed in the sentence, 'the plane is flying over the hill' (Lakoff, 1987). The image-schema of the above sense denotes a spatial relation where the TR is higher than the LM. On this point, above can be used interchangeably with over. A typical example is found in, 'there is a full moon above/over the mountain' (Yule, 2006, p. 129). The third sense of over which is called the covering sense refers to a TR that extends across the edges of a LM. In most cases, the TR is construed as being vertically superior to and in contact with the LM. The scene is coded in the sentence, "the blanket is over the bed" (Riemer, 2010). More figuratively, over is employed very often to convey the concept of preference. Consider the sentence, 'I will take coffee over tea.' Acccording to Lindstromberg (2010), since it is a preposition which suggests upness, this metaphorical sense indicates the idea that if we have to choose one thing among many, we "might mentally place the thing [we] like most on top of the things [we] like less" (p. 120).

\section{- In}

In is used with a bounded LM, having a boundary and an interior. Spatially, in expresses a motionless state in which a TR is inside a LM, and a dynamic sense in which the TR moves along a path towards the interior of the LM (Lindstromberg, 2010). The following diagrams illustrate the meanings of in:

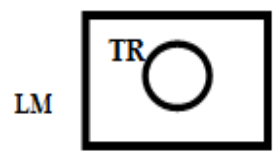

(a)

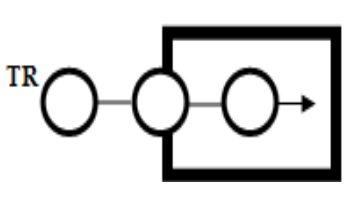

(b)

Figure 06: The Spatial Senses of in (adapted from Lindstromberg, 2010, p. 29) 
For in, the schema (a) shows that the TR (the circle) is enclosed by the LM (the square). For example, in the sentence, "the girl is in the room," the girl is conceptualized as being contained by the LM, the room. This schema represents the central sense of in. The schema (b) depicts the meaning of in when used to express movement. The TR moves along a path towards the interior of a bounded LM. The movement is shown in (b) by the three positions of the TR, going from the outside into the inside of the LM. In this case, the scene can be coded in the sentence, 'put the money in your pocket'. Metaphorically, in is commonly employed to describe abstract concepts such as states, circumstances and moods. Consider the example, 'they're always getting in trouble.' This sense has developed on the basis of the argument that people repeatedly experience a particular emotional state in a given location. The parallel co-existence between location and emotional or physical state becomes established, and through this correlation, people generate "conceptual associations such that they conceptualize and hence lexicalize states in terms of location" (Tylor and Evans, 2003, p. 187).

\section{- Out}

The preposition out is the opposite of in. Its primary sense indicates a spatial relation in which a TR is exterior to a bounded LM, for instance, 'she went out of the room'. Figure 07 shows the central image-schema of out:

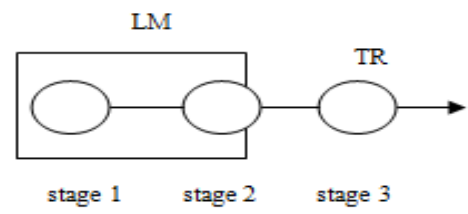

Figure 07: The Central Image-Schema of out (Ungerer \& Schmid, 2006, p. 169)

As the figure shows, the TR moves from being included in the LM to a place where both are totally separated. This is depicted in the figure by the three locations of the TR termed stage 1, stage 2 and stage 3 . Figuratively, out has developed a metaphorical sense to say that something is prevented to be accessed to the interior of something else. The notion of being out designates the notion of exclusion. For example, 'we use mesh screens to keep the insects out' means that by virtue of the mesh screens boundaries, the insects (i.e., the $\overline{\mathrm{TR}}$ ) are kept exterior; that is, excluded from the interior environment (Tylor and Evans, 2003). In addition,

out is often used to talk about a consumable substance if it is not available. When the TR (the consumable entity) is no longer in the container, this means that there is no more of the TR available. For instance, the use of out in "are 
there any more cakes left? No, we're all out!" indicates that there is no more of them (Tylor and Evans, 2003).

\section{- Through}

The basic meaning of through designates a path, along which a TR moves into and then out to the other side of a bounded LM, like in, 'a pigeon flew in through the open window' (Lindstromberg, 2010). The pictorial representation is shown in figure 08 :

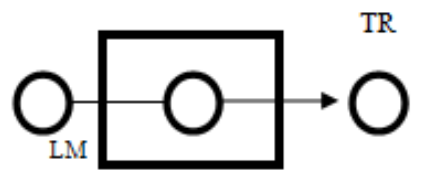

Figure 08: Central Meaning of through

The schema indicates that the TR (the circle) passes from one side to the other of the LM. The arrow represents the movement of the TR that traverses the bounded LM by means of an entrance point and an exit point (Tylor and Evans, 2003). The view of through we have just presented allows us to understand the range of contexts in which it is used metaphorically. Since the LM provides the means whereby the motion is achieved, through often conveys the meaning of the expression 'by means of,' as in, 'the road to success comes through hard work'. Because the spatial scene portrayed by through describes a motion of being out after having entered, it is commonly used to express the notion of being 'out of' or 'finished with' an experience, a task or relationship. This sense can be found in, 'my parents went through a bitter divorce when I was a child,' or 'I'm through with this forum' (Lindstromberg, 2010).

4. Applying Image-Schemas to Learning Polysemous Prepositions: above, across, in, on,

\section{out, over and through}

In the process of teaching prepositions, we have observed that teachers often tend to explain the spatial meanings of the prepositions included in the lesson through using definitions or a list of various prepositions accompanied with illustrative examples. The crux of the problem is that the multiple uses are not addressed although they are essential to ensure that students develop a rich repertoire that fills the lexical gaps in their knowledge because there are myriad of ideas they can speak about using these words. The way polysemous prepositions are dealt with by teachers in the classroom has led us to apply a new form of instruction. Through this study, we aim at examining the effectiveness of applying image-schema-based instruction to teaching the semantics of the English prepositions above, across, in, on, out, over and 
through. Our purpose is to raise the students' awareness of the different senses associated with each preposition by deepening the understanding of the relations and the nuances between them. We hypothesize that applying imageschema based instruction in the classroom would improve the students' outcome and understanding of the target prepositions. We also hypothesize that image-schema based instruction may have a positive impact on the students' attitudes towards applying it to learn polysemous prepositions. In this respect, the study addresses the following research questions:

(a) Can image-schema-based instruction change the learning of polysemous prepositions for the better than the traditional method?

(b) How will the application of image-schema-based instruction be accepted by students of English as a foreign language? That is, to what extend imageschemas help students in the learning/ acquisition of polysemous prepositions.

\subsection{The Experiment}

In order to test the first hypothesis, "applying image-schema based instruction in the classroom would improve the students' outcome and understanding of the target prepositions," effects-of-instruction experiment was conducted. The experiment was broken down into three stages, a pre-test, treatment and a post-test.

The subjects of the study were 80 students from Second Year LMD students studying English as a foreign language at the Department of Letters and English, at the University des Frères Mentouri, Constantine. They were randomly chosen and divided into a Control group $(\mathrm{N}=40)$ and an Experimental group $(\mathrm{N}=40)$. In fact, the sample of the study was about 120 . However, when the post-test was administered, the majority of them did not participate. Hence, only the students who took the pre-test and the post- test were included in the study.

The test employed was made up of two parts. Part I focused on the prepositions above, across, in, on, out, over and through as polysemous items. It aimed at testing the students' awareness of their different senses, and whether they could identify the correct meaning. This is why, part I was a multiple choice exercise where the total number of sentences was 49. For each preposition, students were given three choices of meanings, and they had to choose the correct one. What follows is an example of part I of the test:

E.g.1: 'He suffered a serious bruise above his left eye.'
a) on
b) higher than
c) on top of

Part II, on the other hand, had a forced choice, fill in the blank format. Unlike part I, the purpose of part II was to see whether students could identify the nuances between the target prepositions. Part II focused mainly on situations where the target prepositions seem to mean the same thing. Hence, part II was not made up of sentences. Instead, the activity consisted of a story summarized in a short paragraph. The paragraph had 21 filler items. The students were 
required to fill in the blanks with above, across, in, on, out, over and through without providing them with any choices. They were asked to determine the missing preposition and the appropriate sense that fits the context in the paragraph.

The experiment was conducted over a period of four weeks for two sessions a week and each session lasted 90 minutes. Both the instruction and the tests took place during regular classroom hours. The pre-test was administered on the first day of the experiment to both the Control and Experimental Groups. After the pre-test, the Control Group was taught in the usual way. The teacher used definitions we might find in dictionaries and illustrative examples to explain the meanings of each preposition. The Experimental Group received image-schema- based instruction. The instructional period was meant to depict the meanings via image-schemas as well as to raise the students' awareness of the relation between the different senses of each preposition.

The instruction received by the Experimental Group was divided into three phases, pre-instructional phase, instructional phase and post- instructional phase. In the pre-instructional phase, the students were asked about their background knowledge concerning prepositions in general. The students' attention was directed by the teacher so that they ask questions about the reasons behind the polysemantic nature of prepositions. All the students responded that despite the fact they had studied prepositions many times, they knew only one meaning, while the extended meanings were learnt unconsciously. In the instructional phase, they were provided with a brief description of what a polysemous preposition is, along with presenting the concept of the central meaning which represents a spatial relation between a trajector and landmark element. Then, the teacher explained that the spatial and non-spatial senses of prepositions were related and organized around a central image schema. The meanings of above, across, on, in, out, over and through were illustrated by image-schemas and examples (as they appear in section 3.2). In the post-instructional phase, the students worked in pairs to answer exercises in order to give them more room to discuss and engage them in deep processing of the meanings presented. As homework, the students were required to produce their own sentences to help them use the various meanings in their own words and contexts. Upon completion, the students were asked to provide their answers, followed by the teacher's reaction to their responses through commenting on their correctness. After the instruction, students in the Control and the Experimental Groups took the post-test.

\subsection{Analysis of the Results}

The scoring procedure of the test was as follows. In part I and part II, one point was given for each correct answer, while a wrong answer was given zero. On the basis of this, we applied descriptive statistics (mean, standard deviation 
and percentage) and statistical testing; we used paired t-test to test results within the same group and t-test between the post -tests of both the Experimental Group and Control Group. The alpha level was set at .05.

\subsubsection{Part I}

The following table summarizes the scores of part I of the Control Group and Experimental Group.

Table 1

Descriptive Statistics of Part I of the Test

\begin{tabular}{lllllll}
\hline Groups & \multicolumn{2}{l}{ Control $(\mathrm{n}=\mathbf{4 0})$} & \multicolumn{4}{c}{ Experimental $(\mathrm{n}=40)$} \\
\hline Test & Mean & $\%$ & SD & Mean & $\%$ & SD \\
Pre-test & $\mathbf{1 8 . 7 7}$ & $\mathbf{3 8 . 3 1}$ & $\mathbf{4 . 6 3}$ & $\mathbf{1 7 . 5 5}$ & $\mathbf{3 5 . 8 2}$ & $\mathbf{6 . 0 3}$ \\
Post-test & $\mathbf{1 8 . 1 8}$ & $\mathbf{3 7 . 1 0}$ & $\mathbf{6 . 2 7}$ & $\mathbf{3 3 . 6 2}$ & $\mathbf{6 8 . 6 1}$ & $\mathbf{7 . 2 6}$ \\
\hline
\end{tabular}

Analysis of the results reveals that there is no a statistically significant and remarkable difference between the pre-test and post-test performances in the Control group ( $\mathrm{p}>.50)$. In contrast, in the Experimental Group, we notice an increase of 16.07 (the point estimate $=33.62-17.55$ ) in the mean of correct answers between the pre-test and post-test. This change is very statistically significant ( $p$-value<.0000001). Thus, image-schema based instruction dramatically improves the outcomes of the students. Overall, when we compare between the post-tests of both the Control Group and the Experimental Group, we can see that there is a difference, and the effects of the treatment is statistically significant. We can conclude on the basis of the analysis that the application of image-schemas to teach polysemous prepositions is better than the traditional method ( $\mathrm{p}$-value $<.0001)$.

\subsubsection{Part II}

Table 2 shows the descriptive statistics of fill in the gaps activity scores.

Table 2

Descriptive Statistics of Part II of the Test

\begin{tabular}{lllllll}
\hline Groups & \multicolumn{2}{l}{ Control $(\mathrm{n}=\mathbf{4 0})$} & \multicolumn{4}{c}{ Experimental $(\mathrm{n}=40)$} \\
\hline Test & Mean & $\%$ & SD & Mean & $\%$ & SD \\
Pre-test & $\mathbf{7 . 8}$ & $\mathbf{3 7 . 1 4}$ & $\mathbf{3 . 3 1}$ & $\mathbf{8 . 6 2}$ & $\mathbf{4 1 . 0 4}$ & $\mathbf{3 . 1 8}$ \\
Post-test & $\mathbf{8 . 4}$ & $\mathbf{4 0}$ & $\mathbf{3 . 2 1}$ & $\mathbf{1 3 . 8 8}$ & $\mathbf{6 6 . 0 9}$ & $\mathbf{3 . 3 4}$ \\
\hline
\end{tabular}


The Control group's scores in Table 2 shows very small improvement of 0.6 (8.4- 7.8) from the pre-test to post-test with no statistical significance (pvalue $=.47)$. A glance at Table 2 reveals that the Experimental Group's scores improve strikingly from pre-test to post-test, with a point estimate of 5.26 and $\mathrm{p}$-value $<.000^{*}$. The test scores of the post test of the Experimental group are significantly higher than those of the Control Group $\left(p<.000^{*}\right)$. This means that image-schema-based instruction has proven again that it has an effect on the students' performances when it comes to identifying the nuances that exist between the target prepositions.

\subsection{The Students' Questionnaire}

To test the second hypothesis which has to do with the students' attitudes towards the use of image-schema-based instruction, a questionnaire was administered after the treatment.

\subsubsection{Description of the Questionnaire}

The questionnaire consisted of 18 questions divided into three sections. They included close-ended questions and open-ended ones where students had to explain their choice or suggest alternatives. The first section aimed at getting the students' opinions about their way of learning polysemous prepositions before the treatment. The objective of the second section was to elicit the students' attitudes towards using image-schema- based instruction and the extent to which it helped them to learn polysemous prepositions. The third section was a space devoted to students to give their own comments concerning polysemous prepositions or the application of image-schema-based instruction.

\subsubsection{Analysis of the Questionnaire}

Through the analysis of the Students' Questionnaire, we have come to the conclusion that $76.25 \%$ of students thought that learning polysemous prepositions was a burden. Concerning the way they followed to learn polysemous prepositions, the results revealed that $57.5 \%$ of them relied on their teachers to provide them with a list of meanings and examples. The results also showed that over half the students $(92.5 \%)$ held positive attitudes towards the application of image-schemas in the classroom to teach polysemous prepositions. The students stated that image-schema- based instruction helped them to learn various senses and the difference between them in a short period of time. However, $7.5 \%$ of the students thought that image-schema based instruction is based on abstract diagrams, and they preferred a list of examples and definitions.

\subsection{Overall Analysis}


The findings from this study suggest that image-schema based instruction may improve the learning of above, across, in, on, out, over and through by making students aware of their different senses and the nuances between them. The results indicate that the use of polysemous prepositions constituted a problem for Second Year LMD students. The pre-test showed that they were unconscious of many of the spatial and non-spatial meanings of above, across, in, on, out, over and through as well as the areas where they cannot be used interchangeably. However, on both post-tests, there were statistically significant evidences between the two groups' scores. This means that learners' previous knowledge was modified and consolidated in their minds.

While the traditional instruction affected to some extent the students' performances, image-schema based instruction was more effective on the students' outcomes concerning the use of the target prepositions. The meaningfulness of the information; that is, depicting the senses in imageschemas and building into the students' minds the knowledge of the motivation behind the senses, along with the notion of the central meaning helped learners to remember and use them better than students who were just given the definitions we might find in dictionaries. It also enabled them to engage in deep processing of the target prepositions through giving them an opportunity to process the various senses in different contexts. The study gives reason to believe that students who received instruction based on image-schemas could manage to fill the lexical gaps they had before the instruction.

Tyler and Evans (2004) argued that the representation of meanings as gestalt-like conceptualizations of situations or scenes which are systematically connected in graphic representations rather than a series of separate dictionarytype definitions in a list can provide visual rubrics that may be useful presentational tools for teachers and useful aids for learners

(as cited in Tyler, Mueller \& Ho, 2010a). Our experiment is related to the one conducted by Morimoto \& Loewen in 2007. They observed that imageschema-based instruction was effective because it was easier for learners to understand how different senses, including those in the metaphorical domain, are semantically related because of the image-schema which represented the spatial relationship between the two entities. Besides, it does represent the meanings in a piecemeal fashion. Hence, the hypothesis that applying imageschema-based instruction in the classroom as an alternative instruction to the traditional one promotes better achievements as well as better results is proved.

On the basis of the examination of the data collected from the questionnaire, our second hypothesis has been also confirmed: over half the students were convinced of the importance of presenting the meanings of polysemous prepositions through image-schemas since it can make it clear for them why a single preposition is used in many contexts. Accordingly, it can be deduce that image-schema based instruction has a positive impact on the 
students' attitudes because they perceive that image-schemas are easy to retrieve from memory and therefore act as a useful cue to remember the meanings than just plain words.

One limitation of our study is that the experiment was conducted only on spatial and non-spatial senses. It did not focus on the temporal senses of the target prepositions. Another limitation is that given the multiplicity of meanings of prepositions, the non-spatial senses which were taken into consideration were the metaphorical and not the metonymical. The instruction required students to engage in a radically new way of thinking which required a lot of cognitive demands. This is why, the selected senses were direct and widely agreed upon by researchers.

\section{Conclusion}

The variety of ideas expressed by prepositions makes it an obligation for teachers to deal with more than one sense to enrich and make students' language flexible. Resorting to only examples or rote memorization is not always the best strategy to learn as many meanings as possible. In addition, the representation of meanings associated with prepositions in a piecemeal fashion, rather than as a whole, can confuse the students because each time they encounter varying uses of them. Besides, they will forget the majority of information since their explanation is exclusively based on lists without explaining the systematic relation between the senses.

The type of instruction proposed in this study appears to play a role in developing the learning of polysemous prepositions. Image-schema-based instruction does not only combine between verbal and pictorial illustrations, but also it can present many situations and replace many pictures. Imageschema based instruction has the potential to set a very promising evaluation of the traditional instruction employed in teaching prepositions.

\section{References}

Brenda, M. (2014). The Cognitive perspective on the polysemy of the English preposition

Over. UK: The British Library.

Coventry, K. R., \& Garrod, S. C. (2004). Saying, seeing and acting. The psychological

semantics of spatial prepositions. Essays in Cognitive Psychology Series. Hove and

New York: Psychology Press.

Croft, W. \& Cruse D. A. (2004). Cognitive linguistics. Cambridge: Cambridge University

Press. 
Csábi, S. (2004). A cognitive linguist view of polysemy in English and its implications for teaching. In M. Achard and S. Niemayer (eds), Cognitive linguistics second Language acquisition and foreign language teaching (pp. 233-56). Berlin: Mouton de Gruyter.

Denning, K., Kessler, B., $\quad$ and Leben, W.R.. $\quad$ (2007).English vocabulary elements, New York,

Oxford University Press.

Evans, V. (2007). A glossary of cognitive. Edinburgh, UK: Edinburgh University Press.

Evans, V., \& Green, M. (2006). Cognitive linguistics: An introduction. Mahwah, NJ:

Lawrence Elbaum and Edinburgh : Edinburgh University Press.

Evans, V., \& Tyler, A. (2005). Applying cognitive linguistics to pedagogical grammar: The

English prepositions of verticality. Revista Brasileira de Linguistica Aplicada, 5 (2),1142 .

Gärdenfors, $P$. (2007). Cognitive

Semantics and Image

Schemas with Embodied Forces. In $I$.

M. Krois, M. Rosengren, A. Steidele 81 Westerkamp D.

(Eds.), Embodiment in cognition and culture. Amsterdam, Philadelphia: John Benjamin.

Johnson, M. (1987). The body in the mind: the bodily basis of meaning, imagination,

and reason. Chicago: University of Chicago Press.

Knowles, M. \& Moon, R. (2006). Introducing metaphor, London: Routledge.

Lakoff, G., (1987). Woman, fire and dangerous things. Chicago: University of Chicago

Press.

Langacker, $R . \quad W$. (1987). Foundations of cognitive grammar, Vol. 1: Theoretical prerequisites. Stanford: Stanford University Press.

Lindstromberg, S. (2010). English prepositions explained. Amsterdam: Benjamins.

Lipka, L. (2002). English lexicology lexical structure, word Semantics, and word-Formation

(3rd ed.). Tubingen: Gunter Narr.

Mandler, J.M., \& Pagán Cánovas, C. (2014). On defining image-schemas. Language and 
Cognition, 6 (4), 1-23. doi:10.1017/langcog.2014.14

McGregor, W. (2009). Linguistics: An introduction. London: Continuum.

Murphy, G.L. (2002). The big book of concepts. Cambridge, MA: MIT Press.

Murphy, M. L. (2010). Lexical meaning, Cambridge: Cambridge University Press.

Morimoto, S., \& Loewen, S. (2007). A comparison of the effects of imageschema- based

instruction and translation-based instruction on the acquisition of L2 polysemous words.

Language Teaching Research, 11(3), 347-372.

Nerlich, B. (2003). Polysemy: past and present. In B. Nerlich, Z. Todd, V. Herman, and D.

D. Clarke (eds), Polysemy: Flexible Patterns of meaning in mind and language.

Berlin/New York: Mouton de Gruyter, 49-76.

Radden, G., \& Dirven, R. (2007). Cognitive English grammar. Amsterdam, Philadelphia:

John Benjamins Publishing Company.

Radden, G. \& Kôvecses, Z. (1999). Towards a theory of metonymy. In K. U. Panther \& G.

Radden (Eds.), Metonymy in language and thought (pp. 17- 59). Amsterdam and

Philadelphia: John Benjamins.

Ricoeur, P. (1977). The rule of metaphor: Multi-disciplinary studies in the creation of meaning in language (R. Czerny, K. McLaughlin, \& J. Costello, Trans.).

Toronto: The

University of Toronto Press.

Riemer, N. (2010). Introducing semantics. Cambridge: Cambridge University.

Saeed, J. (2009). Semantics (3rd ed.). Chichester: Wiley-Blackwell.

Soares da Silva, A. (2003). Image-schemas and category coherence: the case of the

Portuguese verb deixar. In H. Cuyckens, R. Dirven \& J. Taylor (eds.), Cognitive

Approaches to Lexical Semantics (pp. 281- 322). Berlin: Mouton de Gruyter.

Taylor, J. R. (1993). Prepositions: Patterns of polusemization and strategies of disambiguation. In C. Zelinsky-Wibbelt (Ed.), The semantics of prepositions.

New York:

Mouton de Gruyter.

Tyler, A. and V.Evans (2003). The Semantics of English prepositions. Cambridge: 
Cambridge University Press.

Tyler, A., Mueller, C., \& Ho, V. (2010a). Applying cognitive linguistics to learning the

Semantics of English to, for and at: An Experimental Investigation. Vigo Internationl

Journal of Applied Linguistics, 8, 181- 206.

Ungerer, F. \& Schmid, H. J. (2006). An Introduction to cognitive linguistics (2nd ed).

Harlow: Pearson Longman.

Yates, J. (1999). The ins and the outs of prepositions: A guide book for ESL students.

Hauppauge, N.Y.: Barron Educational Series.

Yule, G. (2006). Oxford practice grammar advanced: Oxford practice grammar. Oxford:

Oxford University Press.

\section{Note:}

1- In this paper, the terms sense and meaning are used interchangeably 